\title{
Wear Testing and Analysis of Ion Engine Discharge Cathode Keeper
}

\author{
Matthew T. Domonkos, ${ }^{*}$ John E. Foster ${ }^{\dagger}$ and George C. Soulas ${ }^{\ddagger}$ \\ NASA John H. Glenn Research Center at Lewis Field, Cleveland, Ohio 44135
}

\begin{abstract}
Experimental and analytical investigations were conducted to predict the wear of the discharge cathode keeper orifice in the NASA Evolutionary Xenon Thruster. The ion current to the keeper was found to be highly dependent on the beam current, and the average keeper ion current density was nearly identical to that of the NASA Solar Electric Propulsion Technology and Applications Readiness (NSTAR) thruster for comparable beam current density. The ion current distribution was highly peaked toward the keeper orifice. The wear assessment predicted keeper orifice erosion to the same diameter as the cathode tube after processing 250 or $460 \mathrm{~kg}$ of xenon, depending on whether warm or cold ions, respectively, were assumed. Although the presented simple wear analysis does not predict failure, comparison with the NSTAR extended life test results suggests that the discharge cathode assembly will continue to operate beyond the qualification goal of processing $405 \mathrm{~kg}$ of propellant. Probabilistic wear analysis showed that the ion energy at the keeper surface and the sputter yield contributed most to the uncertainty in the wear assessment. It is recommended that fundamental experimental and modeling efforts focus on accurately describing the plasma potential, ion temperature, and the sputtering yield.
\end{abstract}

\section{Nomenclature}

$\begin{array}{ll}a, b, c & =\text { curve fit parameter } \\ E & =\text { energy, } \mathrm{eV} \\ e & =\text { elementary charge, } 1.6 \times 10^{-19} \mathrm{C} \\ f & =\text { yield constant, atoms } / \text { ion } \cdot \mathrm{eV}^{2} \\ f(x) & =\text { distribution function } \\ I & =\text { current, } \mathrm{A} \\ J & =\text { current density, } \mathrm{A} / \mathrm{m}^{2} \\ j & =\text { particle flux, particles } / \mathrm{m}^{2} \cdot \mathrm{s} \\ k & =\text { Boltzmann's constant, } 1.6 \times 10^{-19} \mathrm{~J} / \mathrm{eV} \\ M & =\text { atomic or ionic mass, } \mathrm{kg} \\ N & =\text { number of particles } \\ R & =\text { ratio of double-to-single ion current } \\ r & =\text { radius of the keeper orifice, } \mathrm{m} \\ T & =\text { temperature, } \mathrm{eV} \\ t & =\text { keeper orifice plate thickness, } \mathrm{m} \\ V & =\text { voltage, } \mathrm{V} \\ v & =\text { velocity, } \mathrm{m} / \mathrm{s} \\ V & =\text { volume, } \mathrm{m}^{3} \\ x & =\text { independent variable in distribution function } \\ Y(E) & =\text { ion energy-dependent sputter yield, atoms/ion } \\ \bar{Y} & =\text { average sputter yield for a Maxwellian population, } \\ & \\ \mu & =\text { atoms/ion } \\ \pi & =3.141592 \\ \rho & =\text { mass density, } \mathrm{kg} / \mathrm{m}^{3} \\ \sigma & =\text { log-normal deviation } \\ \tau & =\text { time, } \mathrm{s} \\ & \end{array}$

Presented as Paper 2003-4864 at the AIAA/ASME/SAE/ASEE 39th Joint Propulsion Conference and Exhibit, Huntsville, AL, 20-23 July 2003; received 7 August 2003; revision received 9 September 2004; accepted for publication 9 September 2004. This material is declared a work of the U.S. Government and is not subject to copyright protection in the United States. Copies of this paper may be made for personal or internal use, on condition that the copier pay the $\$ 10.00$ per-copy fee to the Copyright Clearance Center, Inc., 222 Rosewood Drive, Danvers, MA 01923; include the code 0748-4658/05 \$10.00 in correspondence with the CCC.

*Electrical Engineer, On-Board Propulsion Branch, Mail Stop 16-1, Brookpark Road; currently Research Physicist, U.S. Air Force Research Laboratory, 3550 Aberdeen Avenue Southeast, Kirtland Air Force Base, NM 87117. Senior Member AIAA.

${ }^{\dagger}$ Research Engineer, On-Board Propulsion Branch, Mail Stop 16-1, 21000 Brookpark Road.

${ }^{\ddagger}$ Aerospace Engineer, On-Board Propulsion Branch, Mail Stop 16-1, 21000 Brookpark Road.

$$
\begin{array}{ll}
\text { Subscripts } & \\
a & =\text { atom } \\
i & =\text { ion } \\
j & =\text { index } \\
k & =\text { keeper } \\
p & =\text { plasma } \\
\text { th } & =\text { threshold } \\
x & =x \text { component } \\
y & =y \text { component } \\
z & =z \text { component } \\
\Delta V & =\text { component due to potential difference }
\end{array}
$$

Superscripts

$$
\begin{array}{lll}
j & = & \text { species of ion } \\
+ & = & \text { singly charged ions } \\
++ & = & \text { doubly charged ions }
\end{array}
$$

\section{Introduction}

N 2003, ion propulsion systems were deployed on at least 17 active spacecraft performing stationkeeping and primary propulsion duties. ${ }^{1}$ The recently concluded Deep Space 1 (DS1) mission demonstrated the maturity of ion engine technology for primary planetary propulsion applications and led to its selection for the DAWN mission to orbit the asteroids 4 Vesta and 1 Ceres. ${ }^{2}$ The DAWN mission requires three ion engines to process a total of $288 \mathrm{~kg}$ of xenon, more than 2.4 times the flight-qualified throughput of the NASA Solar Electric Propulsion Technology and Applications Readiness (NSTAR) engine. ${ }^{2,3}$ NASA's Evolutionary Xenon Thruster (NEXT) is currently under development for use in a solar electric propulsion stage capable of delivering flagship class spacecraft to the outer planets and for sample return missions. ${ }^{4}$ The variance in the discharge cathode keeper orifice enlargement in ground tests of the NSTAR engine has been demonstrated to be relatively large and possibly a nonlinear function of throttling condition. ${ }^{5-13}$ This investigation seeks to predict the discharge cathode keeper orifice wear in the NEXT ion engine and to address limitations of the accuracy of the predictions.

During the NSTAR development program, three wear tests were performed on the $30-\mathrm{cm}$ engine, and the extended life test (ELT) was the ground test of the flight spare DS1 ion engine. ${ }^{5-9,11-13}$ The first wear test revealed unacceptably high erosion of the discharge cathode assembly, ${ }^{5}$ and the engineering solution was to use a sacrificial keeper maintained at an intermediate potential between the discharge cathode and anode. A subsequent 1000-h wear test validated 
Table 1 Partial NEXT ion engine throttling

\begin{tabular}{|c|c|c|c|c|c|c|c|}
\hline $\begin{array}{l}\text { Anticipated engine } \\
\text { input power, }{ }^{\mathrm{a}} \mathrm{kW}\end{array}$ & $\begin{array}{c}\text { Beam } \\
\text { current, A }\end{array}$ & $\begin{array}{c}\text { Beam power } \\
\text { supply voltage, } \mathrm{V}\end{array}$ & $\begin{array}{l}\text { Accelerator } \\
\text { voltage, } \mathrm{V}\end{array}$ & $\begin{array}{l}\text { Main plenum } \\
\text { flow rate, }{ }^{\mathrm{b}} \mathrm{mg} / \mathrm{s}\end{array}$ & $\begin{array}{l}\text { Discharge cathode } \\
\text { flow rate, }{ }^{\mathrm{b}} \mathrm{mg} / \mathrm{s}\end{array}$ & $\begin{array}{l}\text { Neutralizer flow } \\
\text { rate, }{ }^{\mathrm{c}} \mathrm{mg} / \mathrm{s}\end{array}$ & $\begin{array}{l}\text { Neutralizer keeper } \\
\text { current, A }\end{array}$ \\
\hline 1.07 & 1.20 & 680 & -115 & 1.52 & 0.346 & 0.389 & 3.0 \\
\hline 1.28 & 1.20 & 850 & -125 & 1.52 & 0.346 & 0.389 & 3.0 \\
\hline 1.49 & 1.20 & 1020 & -175 & 1.52 & 0.346 & 0.389 & 3.0 \\
\hline 1.68 & 1.20 & 1180 & -200 & 1.52 & 0.346 & 0.389 & 3.0 \\
\hline 1.94 & 1.20 & 1400 & -220 & 1.52 & 0.346 & 0.389 & 3.0 \\
\hline 2.14 & 1.20 & 1570 & -235 & 1.52 & 0.346 & 0.389 & 3.0 \\
\hline 2.42 & 1.20 & 1800 & -250 & 1.52 & 0.346 & 0.389 & 3.0 \\
\hline 2.40 & 2.00 & 1020 & -175 & 2.63 & 0.375 & 0.428 & 3.0 \\
\hline 2.71 & 2.00 & 1180 & -200 & 2.63 & 0.375 & 0.428 & 3.0 \\
\hline 3.15 & 2.00 & 1400 & -220 & 2.63 & 0.375 & 0.428 & 3.0 \\
\hline 3.49 & 2.00 & 1570 & -235 & 2.63 & 0.375 & 0.428 & 3.0 \\
\hline 3.96 & 2.00 & 1800 & -250 & 2.63 & 0.375 & 0.428 & 3.0 \\
\hline 3.18 & 2.70 & 1020 & -175 & 3.65 & 0.413 & 0.461 & 3.0 \\
\hline 3.61 & 2.70 & 1180 & -200 & 3.65 & 0.413 & 0.461 & 3.0 \\
\hline 4.20 & 2.70 & 1400 & -220 & 3.65 & 0.413 & 0.461 & 3.0 \\
\hline 4.66 & 2.70 & 1570 & -235 & 3.65 & 0.413 & 0.461 & 3.0 \\
\hline 5.30 & 2.70 & 1800 & -250 & 3.65 & 0.413 & 0.461 & 3.0 \\
\hline 4.12 & 3.10 & 1180 & -200 & 4.22 & 0.440 & 0.480 & 3.0 \\
\hline 4.80 & 3.10 & 1400 & -220 & 4.22 & 0.440 & 0.480 & 3.0 \\
\hline 5.33 & 3.10 & 1570 & -235 & 4.22 & 0.440 & 0.480 & 3.0 \\
\hline 6.06 & 3.10 & 1800 & -250 & 4.22 & 0.440 & 0.480 & 3.0 \\
\hline
\end{tabular}

a Nominal values.

${ }^{\mathrm{b}}$ Main-to-discharge cathode flow split selected to result in a 23.5-27 V discharge voltage.

${ }^{\mathrm{c}}$ Neutralizer flow with beam extraction; without beam extraction and for ignition, flow is set to $0.582 \mathrm{mg} / \mathrm{s}$.

Table 2 Selected NSTAR ion engine nominal operating parameters

\begin{tabular}{|c|c|c|c|c|c|c|c|c|}
\hline $\begin{array}{l}\text { Power level } \\
\text { designation }\end{array}$ & $\begin{array}{c}\text { Input } \\
\text { power, }^{\mathrm{a}} \mathrm{kW}\end{array}$ & $\begin{array}{c}\text { Beam } \\
\text { current, }^{\mathrm{b}} \mathrm{A}\end{array}$ & $\begin{array}{c}\text { Beam } \\
\text { voltage, }{ }^{\mathrm{b}} \mathrm{V}\end{array}$ & $\begin{array}{l}\text { Accelerator } \\
\text { voltage, } \mathrm{V}\end{array}$ & $\begin{array}{c}\text { Neutralizer } \\
\text { keeper current, A }\end{array}$ & $\begin{array}{c}\text { Main } \\
\text { flow, mg/s }\end{array}$ & $\begin{array}{c}\text { Discharge } \\
\text { cathode flow, mg/s }\end{array}$ & $\begin{array}{l}\text { Neutralizer } \\
\text { flow, mg/s }\end{array}$ \\
\hline $\mathrm{THO}^{\mathrm{c}}$ & 0.5 & 0.51 & 650 & -150 & 2.0 & 0.58 & 0.24 & 0.23 \\
\hline $\mathrm{TH} 4^{\mathrm{c}}$ & 1.0 & 0.71 & 1100 & -150 & 2.0 & 0.81 & 0.24 & 0.23 \\
\hline TH8 $8^{\mathrm{c}}$ & 1.4 & 1.10 & 1100 & -180 & 1.5 & 1.40 & 0.24 & 0.23 \\
\hline $\mathrm{TH} 10^{\mathrm{c}}$ & 1.7 & 1.30 & 1100 & -180 & 1.5 & 1.67 & 0.25 & 0.24 \\
\hline $\mathrm{TH} 12^{\mathrm{c}}$ & 1.8 & 1.49 & 1100 & -180 & 1.5 & 1.79 & 0.26 & 0.26 \\
\hline $\mathrm{TH} 15^{\mathrm{c}}$ & 2.3 & 1.76 & 1100 & -180 & 1.5 & 2.27 & 0.36 & 0.35 \\
\hline
\end{tabular}

${ }^{\mathrm{a}}$ Nominal values. $\quad{ }^{\mathrm{b}}$ Power supply current or voltage. ${ }^{\mathrm{c}}$ Nominal NSTAR operating condition.

the approach to mitigate discharge cathode wear. ${ }^{6}$ An 8200 -h wear test was conducted on an engineering model NSTAR thruster, and the discharge cathode keeper orifice wear was consistent with the results of a 1000 -h test. ${ }^{6,8,10}$ In the 1000 - and the 8200 -h wear tests, the discharge cathode keeper appeared to erode primarily from its downstream face, presumably from sputtering by ions generated downstream of the assembly. ${ }^{6,7}$ Photographic data taken of the ELT revealed that the discharge keeper orifice diameter was increasing after approximately 4600 -h of operation. ${ }^{10-13}$ An experimental investigation found indirect evidence that the maximum erosion observed in the ELT shifted from the downstream face of the keeper to the keeper orifice during operation at a reduced beam current condition. ${ }^{14}$ The discharge keeper orifice diameter growth during the ELT was observed within the same time period and propellant throughput as the 8200-h test. ${ }^{13}$ A relatively simple analysis of the wear observed in the ELT was conducted, and the variance between the wear in the ELT and its predecessors could not be differentiated within the bounds of uncertainty of the ion flux energy and spatial distributions and of the sputter yield. ${ }^{10}$

A series of experiments were devised and conducted to measure both the ion current and its spatial distribution to the discharge cathode keeper of a NEXT 40-cm engine. The results are presented and discussed. The discharge cathode keeper ion current was also used to make predictions of the erosion of the keeper orifice. A probabilistic wear analysis was developed to assess both the accuracy to which the keeper orifice wear can be predicted and which parameters contribute most to the uncertainty. The analysis is presented along with suggested areas of investigation that will improve prediction accuracy.

\section{Test Hardware and Procedures}

The NEXT 40-cm ion engine is an evolutionary step from the $30-\mathrm{cm}$ NSTAR and DS1 engines. The NEXT engine is designed to process $7 \mathrm{~kW}$, although derating considerations currently limit its maximum power to $6 \mathrm{~kW}$ as shown in Table 1 . The most significant departures from its NSTAR heritage are the $1800-\mathrm{V}$ maximum beam voltage and the increased optics area. The NSTAR throttling appears in Table 2 for reference. Additionally, the discharge cathode has been scaled to provide the extra discharge current required to drive the ion production. Most of the discharge cathode assembly dimensions have increased to accommodate the elevated current, and some other modifications have been implemented, primarily for ease of manufacturing and structural integrity.

To measure the keeper ion current, the discharge cathode keeper was biased below cathode potential. A bias of $20 \mathrm{~V}$ was found to be sufficient to achieve ion saturation. The engine is typically operated for at least $1 \mathrm{~h}$ in discharge-only mode for heating. Ion current measurements are taken only after the engine has run with beam extraction for at least $1 \mathrm{~h}$. Throttling of the engine is accomplished by fixing the flow rates to the cathodes and discharge and adjusting the discharge current to maintain the beam current at a given extraction voltage. At each throttling condition, the engine is operated for at least one-half hour before to measurement of the keeper ion current. All of these time increments are included to achieve steadystate discharge current and to minimize the effects of any thermal transients. Thermal transients were not quantified in this investigation, although qualitative data suggest that they were negligible after one half-hour at a fixed beam current.

The ion current distribution to the keeper orifice plate was measured by increasing the keeper orifice diameter in subsequent tests. Because of time and resource constraints, testing was limited to three diameters beyond the nominal. The two intermediate diameters were chosen because previous experiments ${ }^{10}$ with an NSTAR engine indicated that a proportionally large fraction of the ion current was collected within approximately $2 \mathrm{~mm}$ radially of the keeper orifice for the beginning of life geometry. The configuration with 
the keeper tube only was tested so that the ion current collected by the tube could be subtracted from the results to calculate the ion current collected by the keeper orifice plate.

Uncertainty in the measurement of the keeper ion current arises from the current measurement itself and from biasing the keeper to determine the keeper ion current. The discharge cathode keeper current was measured with a floating digital multimeter to $\pm 0.17 \%$ of reading. The variation in the discharge keeper ion current due to varying the discharge conditions for a constant beam current ranged from a maximum of $2.58 \%$, one standard deviation, at 1.2 -A beam current to $0.69 \%$ at $3.52-\mathrm{A}$ beam. Consequently, the uncertainty in the measured ion current ranged from 0.86 to $2.75 \%$. The method used to measure the ion current collected by the keeper makes two key assumptions: 1) The effect on the surrounding plasma of biasing the keeper significantly negative of cathode is negligible and 2) the change of keeper geometry has a negligible effect on the local plasma and the ion current collected. The current collected by the probe is less than $2 \%$ of the discharge current and less than $7 \%$ of the beam current. The power added to the discharge during these measurements is on the order of $1 \%$ of the discharge power. When it is noted that plasma production near the keeper is dominated by the discharge current and the preceding two observations are used, a rough estimate of the uncertainty introduced by biasing the keeper is $2 \%$. It is recognized that the altered geometry and potential structure likely affect the local plasma properties and, consequently, the calculated ion current density distribution. When the estimates of the power added to the discharge during the measurements of the keeper ion current are considered, a volume-averaged ion production increase of $1 \%$ is assumed as a result of an increase in ion production local to the keeper. Multiplying the estimated, volumeaveraged increase in ion production by the ratio of the total ion current collected by both the ion extraction system and the cathode keeper to that collected just by the keeper results in a conservative estimate of a $15 \%$ overprediction of the keeper ion current. Consequently, the uncertainty in the keeper ion current is estimated to be $+3 /-18 \%$ of the values reported.

\section{Results}

The keeper ion current for NSTAR and the various NEXT geometries is in Fig. 1. The NSTAR data were for a keeper with a copper cap added, thus increasing the surface area. ${ }^{10}$ Consequently, the keeper ion current for NSTAR is less than that shown in Fig. 1. Results are also presented for the NEXT keeper in new condition (full keeper), with 42 and $105 \%$ increases in orifice diameter, with the keeper tube

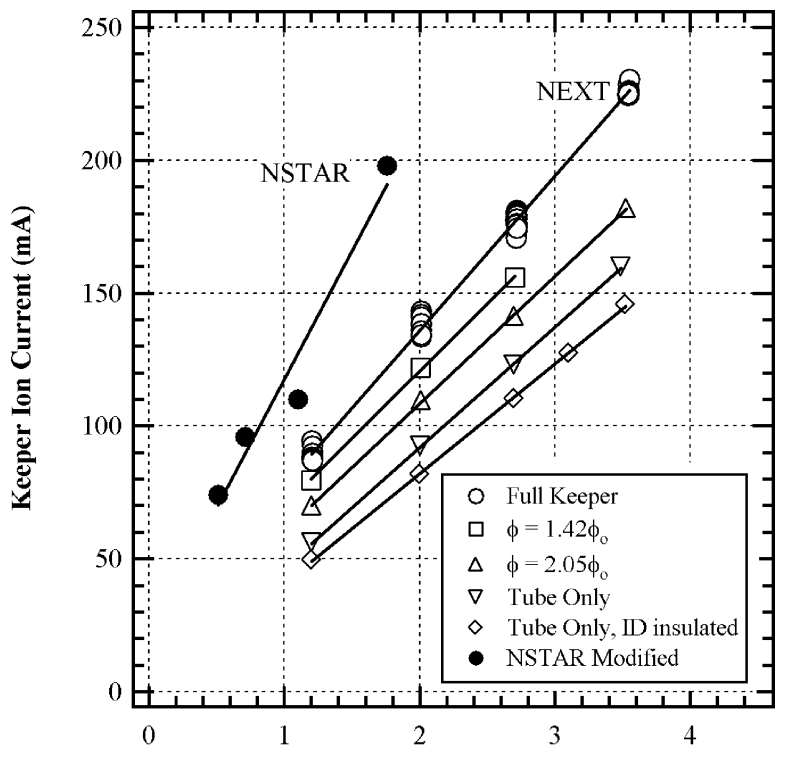

Beam Current (A)

Fig. 1 Measured ion current to the discharge cathode keeper for NEXT with several orifice diameters and NSTAR.

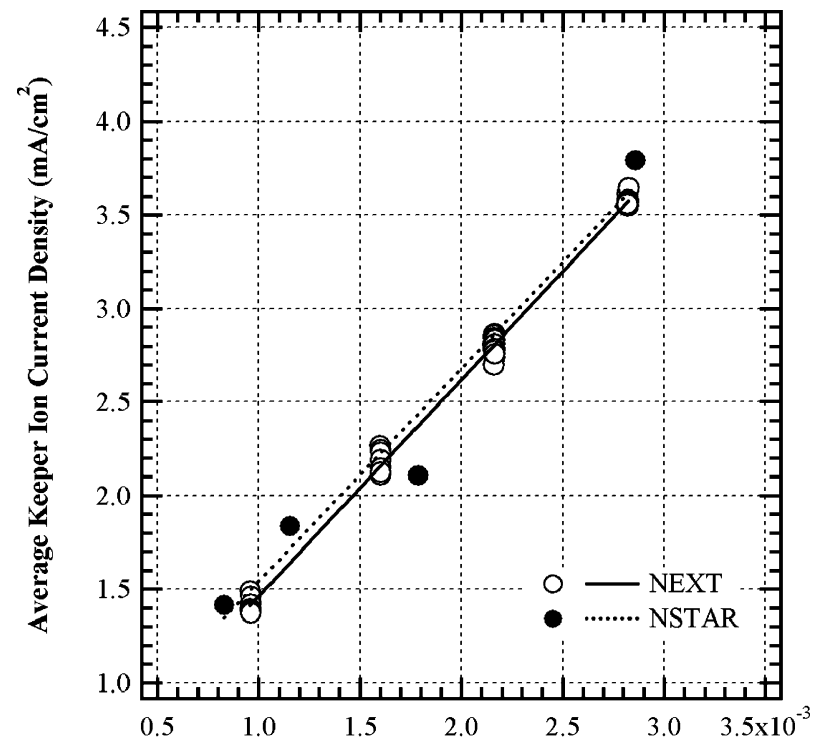

Average Beam Current Density $\left(\mathrm{A} / \mathrm{cm}^{2}\right)$

Fig. 2 Area-averaged ion current density for NEXT and NSTAR are nearly identical.

only, and with the keeper tube with an insulated inner surface. The latter condition is used to determine the fraction of the total keeper ion current that is collected by the orifice plate. The results show the strongly linear relationship between beam current and keeper ion current. The scatter in the data for the NEXT full keeper is the result of varying the discharge efficiency. For the NEXT throttle conditions shown in Table 1,15 linear regression analysis predicts the slope to within $1 \%$. The linearity suggests that ion currents are largely a function of the overall ion production within the discharge chamber. The total plasma production is more strongly a function of the beam current than of the discharge current. The discharge current is adjusted to maintain the beam current, regardless of the cathode and main flows.

The average keeper ion current density for both the NSTAR and NEXT engines is shown in Fig. 2. In both cases, the keeper area includes the entire external surface of the keeper and the orifice of the keeper. The uncertainty of the keeper surface area based on measurements of the keeper is limited by the fabrication to approximately $0.05 \mathrm{~cm}^{2}$. The similarity between NSTAR and NEXT is expected because both engines operate with nearly the same average beam current density. Given the relative ion collection areas of the ion extraction system and the discharge cathode keeper, the beam ion current can be approximated to be dependent on the volume ion production, whereas the ion current to the discharge cathode keeper is more strongly a function of local ion production. Nevertheless, Figs. 1 and 2 indicate that the keeper ion current and the beam current are covariant, and the keeper wear rate is expected to be linearly dependent on the beam current density.

Figure 1 indicates that the keeper ion current decreases faster than the reduction in surface area as the orifice is enlarged for the NEXT discharge cathode assembly (DCA). This result indicates that the local ion density decreases rapidly with increasing radius from the cathode assembly centerline. The distribution of the ion current density as a function of radius was calculated from the data in Fig. 1 and is shown in Fig. 3. The calculation in Fig. 3 assumes that the ion current to the keeper orifice plate is collected on the downstream face; the cylindrical inner diameter of the keeper orifice is neglected only because differentiation of ions collected by this portion of the keeper could not be accomplished. A power-law curve fit is also shown in Fig. 3. The ion current density is highly peaked toward the inner diameter of the keeper orifice plate. Were the energy of the ions bombarding the keeper independent of radius, the rate at which the keeper orifice enlarges would be high when the wear is first observed relative to the wear rate as the keeper orifice diameter 


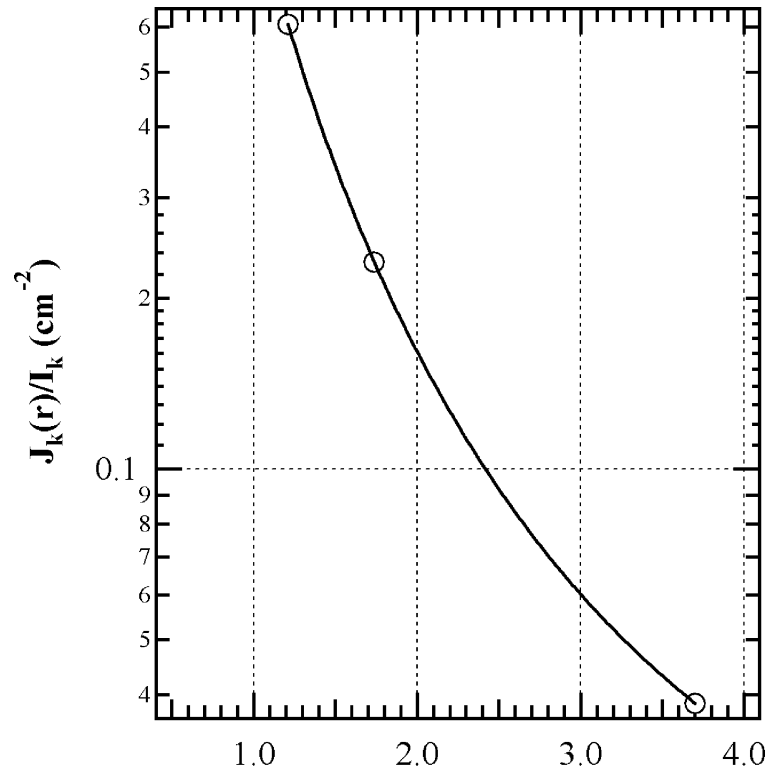

Normalized Keeper Orifice Radius

Fig. 3 Radial distribution of ion current density on the face of the NEXT discharge cathode keeper calculated from data in Fig. 1.

approaches the cathode tube diameter. In fact, the large radial gradient in number density near the cathode orifice likely yields significant radial ambipolar diffusion, and the ion energy and velocity are a nonlinear function of radius. ${ }^{16-19}$

\section{Analysis}

The analysis presented in this report uses a simple sputter erosion model to predict the wear of the discharge cathode keeper in the NEXT ion engine. The wear prediction is a subset of a comprehensive life assessment. As shown by the ELT, erosion of the keeper in itself fails to constitute an end of life condition. ${ }^{13}$ Erosion of the keeper is a step along the way toward two possible failure modes: 1) inability of the cathode to operate within flow rate limits due to erosion of the cathode orifice plate or removal of the orifice plate or 2) inability to restart the discharge due to erosion of the cathode heater. Both of these modes require development of models more sophisticated than that described here. The wear assessment presented here is only sufficient for life assessment if the keeper erosion is modest enough to preclude the development of any failure modes during the qualification life of the thruster. Otherwise additional analysis is needed to verify that the design meets the life requirements.

A goal of the present investigation was to reduce the set of simplifying assumptions of our previous analysis. ${ }^{10}$ Specifically, analysis of the NSTAR ELT discharge keeper erosion is repeated here, with a more rigorous model, to establish bounds for the model parameters used to predict wear of the NEXT DCA. The derived model parameters are then used with the keeper ion current distribution measured in this work to predict the wear of the NEXT discharge cathode keeper. The time to erode the NEXT DCA keeper orifice to the cathode tube diameter was calculated for thermal ion populations to evaluate the effect of this parameter on the solution. Finally, a Monte Carlo technique was used to evaluate the uncertainty in the calculation for use in assigning confidence to the wear prediction, as well as to illuminate the parameters that contribute most strongly to the uncertainty. The latter information may be used to focus research efforts aimed at improving wear prediction.

\section{Model}

The keeper wear predictions are based on a simple model of sputter erosion rate of a material subjected to a known flux of ions with a given energy,

$$
\frac{\mathrm{d} N}{\mathrm{~d} \tau}=j^{+} Y\left(E^{+}\right)+j^{++} Y\left(E^{++}\right)
$$

Equation (1) assumes that the singly and doubly charged ion fluxes are the only contributors to sputter erosion. This assumption is based on the negligibly small triply charged ion current fraction observed in the beam of xenon ion thrusters operated at discharge voltages on the order of $25 \mathrm{~V}$, as well as emission spectroscopic observations of an NSTAR discharge chamber during beam extraction. ${ }^{20}$ Although not generally reported, the ratio of double-to-single ion current measured in the beam, neglecting higher charged states, is typically sufficient to assess efficiency losses due to multiply charged ions. ${ }^{21}$ The yield equation was taken to be of the form recommended by Mantenieks. $^{22}$

$$
Y(E)=f\left(E-E_{\mathrm{th}}\right)^{2}
$$

(also see Ref. 23). More sophisticated models exist for the sputter yield near threshold, however, the spread in experimental data argues against adoption of a particular model on the grounds of validation against data. The model recommended by Mantenieks matches the measured erosion at $100 \mathrm{eV}[\mathrm{Y}(100 \mathrm{eV})]$ and uses the experimentally determined sputter threshold. ${ }^{22}$ Equation (2) simplifies the inclusion of the uncertainty in both the sputtering magnitude and threshold.

Either cold or thermal ions may be considered in Eqs. (1) and (2). When considering a cold ion population, the ion energy was calculated to be the energy of an initially stationary ion falling through the potential difference between the plasma and keeper potentials,

$$
E^{+}=k\left(V_{p}-V_{k}\right), \quad E^{++}=2 k\left(V_{p}-V_{k}\right)
$$

Alternatively, thermal ion populations were also considered in the analysis. In a one-dimensional approximation, ions in the zero drift population, at the plasma potential, and with a velocity component toward the keeper face were assumed to strike the keeper. In addition to the thermal component of their velocity toward the keeper, a drift component was added based on the potential difference between the plasma and keeper. If motion toward the keeper is considered in the positive $z$ direction, then the $z$ component of velocity of ions at the keeper surface is

$$
\begin{aligned}
& v_{z}^{+}=v_{z, \mathrm{th}}^{+}+v_{z, \Delta V}^{+}=v_{z, \mathrm{th}}^{+}+\sqrt{2 e\left(V_{p}-V_{k}\right) / M_{i}} \\
& v_{z}^{++}=v_{z, \text { th }}^{++}+v_{z, \Delta V}^{++}=v_{z, \text { th }}^{++}+\sqrt{4 e\left(V_{p}-V_{k}\right) / M_{i}}
\end{aligned}
$$

The $z$ velocity component is combined with the $x$ and $y$ components to evaluate the yield due to each ion population $j$,

$$
\begin{aligned}
\bar{Y}^{j}= & \left(\int_{-\infty}^{\infty} \mathrm{d} v_{x}^{j} \int_{-\infty}^{\infty} \mathrm{d} v_{y}^{j} \int_{0}^{\infty} \mathrm{d} v_{z, \mathrm{th}}^{j} Y\left(v_{x}^{j}, v_{y}^{j}, v_{z, \mathrm{th}}^{j}+v_{z, \Delta V}^{j}, E_{\mathrm{th}}\right)\right. \\
& \left.\times\left(\frac{m}{2 \pi k T_{i}^{j}}\right)^{\frac{3}{2}} \exp \left\{-\frac{m}{2 k T_{i}^{j}}\left[\left(v_{x}^{j}\right)^{2}+\left(v_{y}^{j}\right)^{2}+\left(v_{z, \mathrm{th}}^{j}\right)^{2}\right]\right\}\right) \\
& \left(\int_{-\infty}^{\infty} \mathrm{d} v_{x}^{j} \int_{-\infty}^{\infty} \mathrm{d} v_{y}^{j} \int_{0}^{\infty} \mathrm{d} v_{z, \mathrm{th}}^{j}\left(\frac{m}{2 \pi k T_{i}^{j}}\right)^{\frac{3}{2}}\right. \\
& \left.\times \exp \left\{-\frac{m}{2 k T_{i}^{j}}\left[\left(v_{x}^{j}\right)^{2}+\left(v_{y}^{j}\right)^{2}+\left(v_{z, \mathrm{th}}^{j}\right)^{2}\right]\right\}\right)
\end{aligned}
$$

Equation (5) was evaluated for singly and doubly charged ion populations of temperature $T_{i}$, and the result was used in Eq. (1). Note that the sputter yield in Eq. (5) is written as a function of the threshold energy and the velocity components because they define the ion energy.

The sputter yield is also a function of the incident ion angle. Under the assumption of a Maxwellian ion distribution with negligible 
bulk velocity, relatively few ions in the tail of the distribution will impact the keeper at large angles; using the Monte Carlo program SRIM-2003, the sputter yield for near normally incident xenon ions on molybdenum was calculated to differ from that of normally incident ions by only a few percent. In the present investigation, the mean ion angle of incidence with the keeper face was calculated to be 20 and $15 \mathrm{deg}$ from normal incidence for the singles and doubles, respectively, for the warm ion case to be discussed. Up to $30 \mathrm{deg}$ from normal incidence, the sputter yield is less than for normal incidence. Consequently, using the normally incident value of the sputter yield will result in a conservative estimate of the wear rate.

To solve for the flux of singly and doubly charged ions incident on the keeper, the double-to-single ion current ratio is substituted. The double-to-single ion current ratio is given by

$$
R=I_{k}^{++} / I_{k}^{+}=2 j^{++} / j^{+}
$$

The keeper ion current is written in terms of the singly and doubly charged ion fluxes as follows:

$$
I_{k}=e j^{+}+2 e j^{++}
$$

Solving Eqs. (6) and (7) for the singly and doubly charged ion fluxes in terms of experimentally determined parameters yields

$$
\begin{aligned}
j^{+} & =\left(I_{k} / e\right)[1 /(1+R)] \\
j^{++} & =\left(I_{k} / 2 e\right)[R /(1+R)]
\end{aligned}
$$

To compare with erosion observations, the volume of eroded material must be calculated. The volumetric erosion rate is related to the sputter erosion rate defined in Eq. (1) by the effective volume of an atom of the sputtered material,

$$
\forall_{a}=M_{a} / \rho
$$

The spatial distribution of the ion current enables further comparison with experimental results. A power law curve fit of the data in Fig. 3 is used to describe analytically the current density on the keeper orifice plate as a function of radius and beam current,

$$
J_{k}(r)=I_{k}\left[a+b r^{c}\right]
$$

When it is assumed that the ions sputter the keeper from the downstream surface only ${ }^{8}$ and that the erosion rate is independent of time or keeper geometry, the keeper orifice diameter as a function of time can be calculated. Substitution of the current density calculated in Eq. (10) for the keeper ion current in the volumetric erosion rate yields the rate of decrease of keeper thickness as a function of radius,

$$
\frac{\mathrm{d} t(r)}{\mathrm{d} \tau}=\frac{J_{k}(r)}{e}\left[\frac{1}{1+R} Y\left(E^{+}\right)+\frac{R}{2(1+R)} Y\left(E^{++}\right)\right] \forall_{a}
$$

The keeper thickness is then used to calculate the time for wear through at a given radius. The authors note that increases in the keeper orifice likely alter the energetics of the ions striking the keeper surface; however, both additional experimental data and a more detailed model are needed to consider this phenomenon in a wear assessment.

\section{Parameter Distributions}

The calculations of the keeper erosion in the present work depend on experimentally determined parameters. Measurements of the sputter yield as a function of ion energy, the ion temperature, the plasma potential, the ratio of double-to-single ion current, and the ion current distribution on the keeper reported in the literature vary. The experimentally determined values are reviewed next. The particular values used in modeling the erosion of the NEXT discharge cathode keeper were chosen by validation against NSTAR erosion measurements, within the bounds of each parameter reported in the literature.
The energy of the ions striking the keeper is a function of the potential distribution surrounding the keeper and the ion temperature. Typically laser-induced fluorescence (LIF), heat flux probes, or energy analyzer probes are the experimental techniques used to measure ion energy distributions, which if appropriate may be used to describe the temperature. To the authors' knowledge, only LIF has been used to examine the energetics of the ion population within an ion thruster discharge chamber. ${ }^{18,19}$ Williams $^{18}$ and Williams et al. ${ }^{19}$ used LIF to measure the axial and radial velocities of singly ionized xenon in an NSTAR derivative ion engine. The ion population outside of the sheath was nonisotropic and exhibited axial energies ranging from approximately 0.3 to $2.7 \mathrm{eV}$ for keepered operation. ${ }^{18,19}$ The total energy of the ions was as high as $10.5 \mathrm{eV}$ for the keepered conditions, and in some radial locations, the bulk velocity was directed away from the keeper. ${ }^{19}$ Measurements of the ion energy distribution using energy analyzers downstream of a discharge chamber were also considered in assessing the ion energy input for the wear predictions. ${ }^{16,24,25}$ Kameyama and Wilbur ${ }^{24}$ observed a high-energy tail on the energy distribution of the ions emitted from a hollow cathode similar to those used in the NSTAR program. Williams et al. ${ }^{25}$ also used a cathode similar to that in the NSTAR engine and measured ion energy distributions of up to approximately $20-\mathrm{eV}$ full width, half-maximum (FWHM). Foster and Patterson ${ }^{16}$ measured the ions emitted from the discharge chamber of an NSTAR ion engine without beam extraction. The FWHM ion energy observed by Foster and Patterson ${ }^{16}$ ranged from approximately 14 to $21 \mathrm{eV}$. In each case, ${ }^{16,24,25}$ the measured ion energy was for ions directed away from the cathode assembly, downstream of the region of interest, and in the absence of beam extraction. Nevertheless, the observations provide an upper bound on the ion energy to be used in the model.

Although experimental techniques to measure plasma potential are well developed, few data have been published on the plasma potential within an ion engine discharge chamber during beam extraction. ${ }^{26}$ The results by Beattie and Matossian ${ }^{26}$ with a mercury ion engine indicated a plasma potential of up to $7 \mathrm{~V}$ above the discharge voltage during beam extraction. Foster and Patterson ${ }^{16}$ have recently measured plasma potential distributions in an NSTAR ion engine discharge chamber without beam extraction, finding that the plasma potential is generally between anode and cathode potentials. The plasma potential was found to peak just below the discharge voltage, between 8 and $10 \mathrm{~mm}$ from the cathode axis, and drop to $12-14 \mathrm{~V}$ approaching the centerline. Herman and Gallimore have recently measured plasma potential distributions in an NSTAR derivative ion engine discharge chamber with beam extraction and found that the plasma potential is generally between anode and cathode potentials. ${ }^{27}$ Consequently, plasma potentials between $12 \mathrm{~V}$ below and $7 \mathrm{~V}$ above the discharge potential were considered in the model.

The ratio of double-to-single ion current to the keeper has yet to be measured accurately, and most analyses related to the NSTAR ion engine rely on the measurement from an ExB probe placed far downstream of the thruster. ${ }^{6-9,11-14,21}$ The measurements of the double-to-single ion current ratio in the plume range from approximately 0.02 (Ref. 21) to 0.34 (Ref. 7) generally increasing with power. For the NSTAR ExB measurements, the probe sampled a strip from 1.6 to $3.1 \mathrm{~cm}$ wide across the diameter of the ion engine, and the documented ratio must be considered to be volume weighted..$^{6-9,11-13}$ These data can be corrected for the conditions near the ion optics by modeling the charge exchange environment between the probe and the thruster. Correction for the environment near the keeper requires more rigor, including model development and validation. Whereas additional experimentation and analytical investigation are necessary to quantify the ratio of double-tosingle ion current on the keeper accurately, a conservative estimate would fix the ratio at or slightly above that measured downstream. Within the discharge chamber, the electron current density, and consequently the ionization, is greatest near the cathode orifice, and intuitively the local density of doubly charged ions would be greater than or equal to the volume-averaged value observed by a probe far downstream. 
The total and distributed ion current to the keeper was measured in this investigation, and the error associated with the measurement was discussed earlier. The keeper ion current for the full keeper was measured for varying discharge chamber efficiencies at constant beam current, and the resulting scatter is shown in Fig. 1. The standard deviation for the scatter is less than $2.5 \%$ for all beam currents. The magnitude of the keeper ion current and its distribution were taken from the experimental data reported in this paper.

The form of the sputter yield used in this investigation was described previously. Duchemin et al. ${ }^{28}$ summarized sputtering yield data and theory near threshold, illustrating the uncertainty in sputter yields near threshold. A conservative approach was adopted for this investigation, using as the median values the yield reported by Rosenberg and Wehner ${ }^{29}$ at $100 \mathrm{eV}$, and the minimum threshold for sputtering molybdenum of between 24 and $27 \mathrm{~V}$ (Refs. 22 and 30). Given the spread in experimental data and analytical results compiled by Duchemin et al., ${ }^{28}$ the sputter yield appears to be nearly as uncertain as the ratio of double-to-single ion current to the keeper.

\section{Validation Against NSTAR ELT}

Estimated Erosion in ELT

Three scenarios were considered for the photographically observed discharge keeper erosion during the extended life test of the DS1 flight spare ion engine. The first scenario was that the orifice eroded uniformly from the inner diameter and that the wear was purely radial with no axial variation. The second scenario was that the orifice wear was radial and included a 45-deg chamfer as observed in the photographs. ${ }^{11}$ The third and worst-case scenario included the second scenario along with uniform erosion from the downstream surface at the maximum rate observed in previous wear tests, $70 \mu \mathrm{m} / \mathrm{kh}$ (Refs. 8 and 10). The estimated erosion observed in the NSTAR ELT is shown in Fig. 4 for each of the scenarios. Although the particular erosion pattern observed in the ELT was markedly different from that of previous wear tests, the contribution of the orifice enlargement in relation to the projection of uniform wear across the keeper orifice plate is $10-30 \%$ over the duration shown in Fig. 4.

\section{Calculation of ELT Keeper Erosion}

Also presented in Fig. 4 are calculations of the keeper wear in the ELT using the discharge voltage, keeper voltage, and the beam current. For the cold ion case, the yield was calculated directly from Eqs. (2) and (3). The volumetric erosion rate was calculated from Eq. (1) and integrated over the test duration to yield the volume

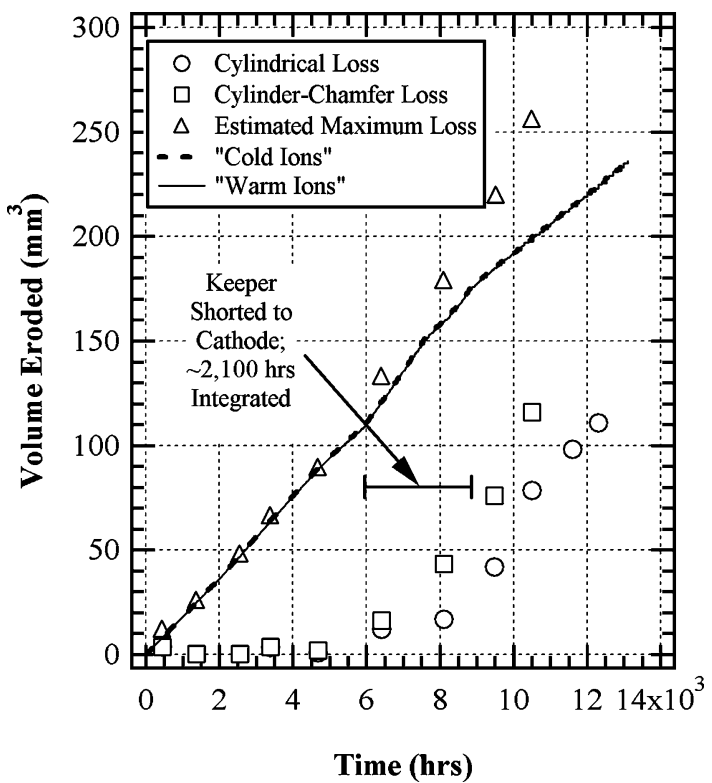

Fig. 4 NSTAR ELT estimated erosion and model predictions for both warm and cold ion populations. of material eroded as a function of time. The plasma potential, the double-to-single ion current ratio, and the sputtering threshold voltage were allowed to vary within the bounds discussed earlier until a fit was obtained that matched the worst case of the estimated erosion. The resultant calculation matches the ELT wear until the cathode and keeper became intermittently shorted. To match the worst-case wear at late times, the initial wear would have to exceed the worst case. The parameters for the cold ion case are in Table 3 .

The warm ion calculation is also shown in Fig. 4. It lies essentially on top of the cold ion calculation. In this case, Eq. (5) was numerically evaluated for singly and doubly charged ions at each data point for the ELT over the duration shown in Fig. 4. Equation (1) was evaluated and integrated over time in the same fashion described for the cold ion case. For the warm ions, the model parameters were also varied within the bounds described earlier. The resultant parameters for the warm ion case are also in Table 3. A 5-eV ion population was chosen largely to straddle the various ion energy measurements. ${ }^{16,19,24,25}$ Other values of the ion temperature were tried in the model. Closer to the cold ion case, the tail of the energy distribution for singly charged ions yields an increasingly small contribution. One criticism of the assumption of cold ions is that it neglects the effect of the tail of the energy distribution for the singly charged ions. In fact, the plasma potential for the cold ion case is sufficiently high that the singly charged ions contribute to the wear of the keeper throughout the first 13,131 h of the ELT. Temperatures greater than $5 \mathrm{eV}$ require the remaining parameters to be outside the range of experimental evidence. The comparatively wide energy distribution results in a plasma potential $14 \mathrm{~V}$ lower than in the cold ion case and consistent with the discharge only measurements of Foster and Patterson. ${ }^{16}$

\section{Analysis of NEXT Discharge Cathode Assembly}

When the parameters derived earlier were used, the wear of the NEXT discharge keeper was predicted. The data of Fig. 3 were used in Eq. (11) to define an erosion rate (depth/time) as a function of radius. Although Table 1 lists nominal values for the discharge

Table 3 Model parameters used to match wear in NSTAR ELT

\begin{tabular}{lcc}
\hline \hline Property & Cold ion case & Warm ion case \\
\hline$T_{i}, \mathrm{eV}$ & 0 & 5.0 \\
$V_{p}, \mathrm{~V}$ & $V_{d}+7$ & $V_{d}-7$ \\
$V_{\mathrm{th}}, \mathrm{V}$ & 24.0 & 27.0 \\
$Y(100 \mathrm{eV})^{\mathrm{a}}$ & 0.06 & 0.06 \\
$R$ & 0.21 & 0.25 \\
\hline \hline
\end{tabular}

${ }^{\text {a Atoms/ion }}$

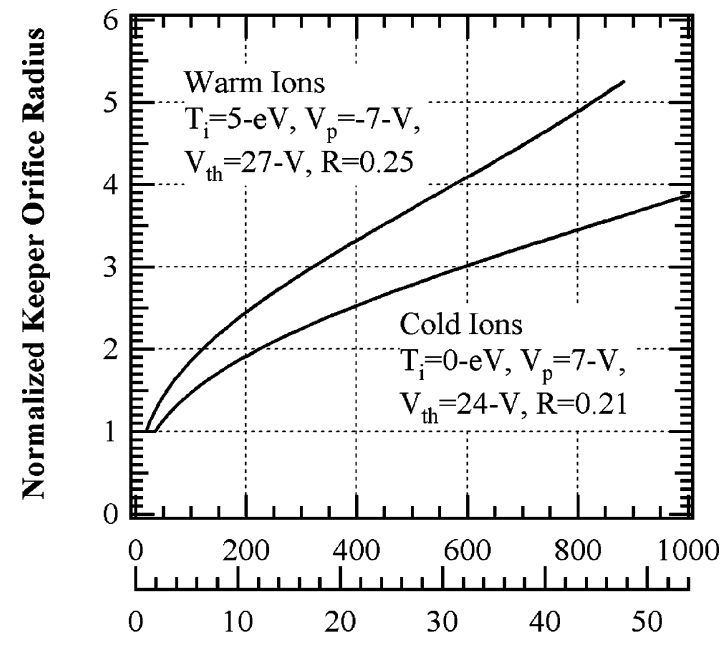

Propellant Throughput (kg) / Time (khrs)

Fig. 5 Deterministic predictions of NEXT discharge cathode keeper orifice wear showing a large difference in wear between warm and cold ion assumptions. 
voltage in the NEXT ion engine, the average values of the discharge voltage and keeper voltage for the ELT over the first 13,131 h were used to be consistent with the validation analysis. The discharge and keeper voltages were assumed to be 25 and $3.5 \mathrm{~V}$, respectively. The predicted times to wear through the keeper thickness as a function of radius for both the cold and warm ion assumptions are in Fig. 5. The warm ion prediction clearly represents a more conservative result, and the magnitude of the difference between the predictions loosely illustrates the limitations of any erosion prediction where the ion temperature and plasma potential are as poorly known as in this analysis.

Under the assumption that the ions streaming back toward the keeper are generated downstream of the keeper orifice plate, then as the orifice diameter increases, the cathode orifice plate becomes increasingly subject to ion bombardment. The time required to increase the keeper orifice diameter to that of the cathode tube can be used as an indirect measure of the ability of the discharge cathode assembly to meet throughput requirements of the engine. If the propellant throughput consumed when the keeper orifice has eroded to the cathode tube diameter is a large fraction of the qualification throughput, the experience of the ELT suggests that keeper wear

\begin{tabular}{|c|c|c|c|}
\hline \multirow[b]{2}{*}{ Parameter } & \multirow[b]{2}{*}{ Median } & \multicolumn{2}{|c|}{ Confidence, $\%$} \\
\hline & & 70 & 96 \\
\hline$T_{i}, \mathrm{eV}$ & 0.050 & $\begin{array}{l}+0.001 \\
-0.001\end{array}$ & $\begin{array}{l}+0.002 \\
-0.002\end{array}$ \\
\hline$V_{p}, \mathrm{~V}$ & 32.0 & $\begin{array}{l}+0.3 \\
-0.3\end{array}$ & $\begin{array}{l}+0.8 \\
-0.6\end{array}$ \\
\hline$V_{\mathrm{th}}, \mathrm{V}$ & 24.0 & $\begin{array}{l}+0.3 \\
-0.2\end{array}$ & $\begin{array}{l}+0.6 \\
-0.5\end{array}$ \\
\hline$R$ & 0.210 & $\begin{array}{l}+0.002 \\
-0.002\end{array}$ & $\begin{array}{l}+0.005 \\
-0.004\end{array}$ \\
\hline$Y(100)$ & 0.060 & $\begin{array}{l}+0.001 \\
-0.001\end{array}$ & $\begin{array}{l}+0.002 \\
-0.002\end{array}$ \\
\hline$J_{k}, \mathrm{~A}$ & 0.224 & $\begin{array}{l}+0.003 \\
-0.002\end{array}$ & $\begin{array}{l}+0.005 \\
-0.005\end{array}$ \\
\hline Throughput, kg & 381 & $\begin{array}{l}+25 \\
-21\end{array}$ & $\begin{array}{l}+54 \\
-41\end{array}$ \\
\hline Time at 3.1-A, hrs & 20,600 & $\begin{array}{l}+1300 \\
-1200\end{array}$ & $\begin{array}{l}+2900 \\
-2200\end{array}$ \\
\hline
\end{tabular}

will not inhibit the engine from achieving the design goals. During the ELT, the discharge keeper orifice diameter opened to the cathode tube diameter after the engine had processed just $31 \%$ of the $235 \mathrm{~kg}$ of propellant it ultimately consumed. Based on the warm ion assumption, the NEXT discharge keeper orifice would enlarge to the cathode tube diameter after processing $63 \%$ of the $400-\mathrm{kg}$ qualification target. Although this analysis cannot conclusively determine whether keeper erosion in the NEXT engine will enable or prevent achievement of the qualification target, the experience of the NSTAR wear tests, particularly the ELT, suggests that the keeper wear rate is sufficiently low to attain the qualification goal.

Probabilistic wear analysis, using Monte Carlo techniques, was employed to quantify the uncertainty in the erosion calculations caused by the uncertainty in the experimentally determined parameters. The spread in the results in Fig. 5 complicates analysis of the design. Because existing experimental results ${ }^{18}$ indicate that the ion population is warm, the warm ion case must be considered to be more representative of reality. Nevertheless, the uncertainty in this prediction cannot be defined in the absence of either a validated plasma model of the discharge chamber or ion temperature data for NEXT operating conditions and their uncertainty. Part of the motivation for the probabilistic wear analysis was to determine the experimental efforts that will have the greatest impact on erosion calculations. Additionally, the probabilistic wear assessment may also be used to evaluate the minimum attainable uncertainty in any wear prediction based on Eqs. (1) or (11), incorporating experimental results.

The probabilistic wear analysis was conducted by using essentially the same physics as described earlier, but allowing the input parameters to vary, according to a statistical distribution, over a range to assess the effect of the uncertainty in each parameter on the predicted wear. A log-normal distribution function was assumed for the ranges of ion temperature, plasma potential, and sputtering threshold voltage, the magnitude of the sputtering yield for $100-\mathrm{eV}$ ions, and the total ion current to the keeper. Note that the concept of the ion temperature still represents Maxwellian velocity distributions, whereas the distribution of temperatures is given a log-normal distribution in this analysis. The log-normal distribution function was chosen for numerical simplicity because it avoids nonphysical, negative values of the parameters in the model. The choice of distribution function will affect the results, but as the uncertainties in the model inputs become better known, the analysis presented here should be refined. The log-normal distribution function is defined as

$$
f(x)=(1 / \sqrt{2 \pi} \sigma x) \exp \left\{-\left(1 / 2 \sigma^{2}\right)[\ln (x)-\mu]^{2}\right\}
$$

Table 5 Effect of the uncertainty in model parameters on the calculated throughput and time to wear keeper orifice to the cathode tube diameter at 3.1-A beam current for the cold ion case

\begin{tabular}{|c|c|c|c|c|c|c|c|c|c|}
\hline \multicolumn{4}{|c|}{ Varied parameter information } & \multicolumn{3}{|c|}{ Throughput, kg } & \multicolumn{3}{|c|}{ Time at 3.1-A, hrs } \\
\hline \multirow[b]{2}{*}{ Parameter } & \multirow[b]{2}{*}{ Median } & \multicolumn{2}{|c|}{ Confidence, $\%$} & \multirow[b]{2}{*}{ Median } & \multicolumn{2}{|c|}{ Confidence, $\%$} & \multirow[b]{2}{*}{ Median } & \multicolumn{2}{|c|}{ Confidence, $\%$} \\
\hline & & 70 & 96 & & 70 & 96 & & 70 & 96 \\
\hline \multirow[t]{2}{*}{$\overline{T_{i}, \mathrm{eV}}$} & 0.050 & +0.005 & +0.013 & 381 & +25 & +55 & 20,600 & +1300 & +3000 \\
\hline & & -0.005 & -0.009 & & -22 & -42 & & -1200 & -2300 \\
\hline \multirow[t]{2}{*}{$T_{i}, \mathrm{eV}$} & 0.050 & +0.014 & +0.039 & 381 & +27 & +59 & 20,600 & +1500 & +3200 \\
\hline & & -0.010 & -0.018 & & -23 & -45 & & -1300 & -2400 \\
\hline \multirow[t]{2}{*}{$V_{p}, \mathrm{~V}$} & 32.0 & +3.5 & +8.8 & 375 & +285 & +767 & 20,300 & $+15,400$ & $+41,400$ \\
\hline & & -3.0 & -5.5 & & -145 & -229 & & -7900 & $-12,400$ \\
\hline \multirow[t]{2}{*}{$V_{\mathrm{th}}, \mathrm{V}$} & 24.0 & +2.6 & +6.6 & 382 & +98 & +208 & 20,700 & +5300 & $+11,300$ \\
\hline & & -2.3 & -4.1 & & -72 & -121 & & -3900 & -6500 \\
\hline \multirow[t]{2}{*}{$R$} & 0.210 & +0.023 & +0.058 & 381 & +35 & +78 & 20,600 & +1900 & +4200 \\
\hline & & -0.020 & -0.036 & & -30 & -58 & & -1600 & -3100 \\
\hline \multirow[t]{2}{*}{$R$} & 0.210 & +0.057 & +0.162 & 382 & +66 & +147 & 20,600 & +3500 & +7900 \\
\hline & & -0.044 & -0.076 & & -52 & -96 & & -2800 & -5200 \\
\hline \multirow[t]{2}{*}{$Y(100)$} & 0.060 & +0.0064 & +0.015 & 383 & +47 & +103 & 20,700 & +2600 & +5600 \\
\hline & & -0.0055 & -0.010 & & -41 & -76 & & -2200 & -4100 \\
\hline \multirow[t]{2}{*}{$Y(100)$} & 0.060 & +0.016 & +0.041 & 384 & +105 & +247 & 20,700 & +5700 & $+13,400$ \\
\hline & & -0.012 & -0.021 & & -80 & -142 & & -4300 & -7700 \\
\hline \multirow[t]{2}{*}{$J_{k}, \mathrm{~A}$} & 0.224 & +0.024 & +0.055 & 382 & +47 & +107 & 20,700 & +2500 & +5800 \\
\hline & & -0.021 & -0.037 & & -41 & -76 & & -2200 & -4100 \\
\hline \multirow[t]{2}{*}{$J_{k}, \mathrm{~A}$} & 0.224 & +0.061 & +0.152 & 380 & +106 & +249 & 20,500 & +5800 & $+13,500$ \\
\hline & & -0.045 & -0.078 & & -77 & -138 & & -4200 & -7400 \\
\hline
\end{tabular}


The erosion rate was calculated for 12,000 different combinations of model parameters. In each iteration, 2000 ions, randomly distributed in velocity space according to a Maxwellian ion temperature, were used to derive the sputter yield of the singly and doubly charged ions. The number of particles in each iteration and the number of iterations were evaluated for convergence to within $1 \%$ for the median.

The results of the probabilistic analysis are in Tables 4 and 5 for the cold ion assumption and Tables 6 and 7 for the warm ion assumption. A small, finite, temperature of $0.05 \mathrm{eV}$ was used in the cold ion assumption so that the effect of the realistically expected uncertainty in the ion temperature could be evaluated. Because the log-normal distribution is asymmetric, the median differs from the mean, and the median is reported along with 70 and $96 \%$ confidence bands. The asymmetry of the log-normal distribution leads to a larger range in the confidence band above the median. The variation in the median values for throughput and time at the 3.1-A beam condition is essentially negligible given the uncertainty in all of the cases. The nominal parameter uncertainties were chosen based on the minimum possible for numerical stability.

The nominal median throughput to erode the keeper orifice to the cathode tube diameter for the cold ion case is $381 \mathrm{~kg}$ with $96 \%$

Table 6 Calculated throughput and time to wear keeper orifice to the cathode tube diameter at 3.1-A beam current for the nominal warm ion case

\begin{tabular}{lccc}
\hline \hline & & \multicolumn{2}{c}{ Confidence, \% } \\
\cline { 2 - 4 } Parameter & Median & 70 & 96 \\
\hline$T_{i}, \mathrm{eV}$ & 5.00 & +0.05 & +0.10 \\
& & -0.05 & -0.10 \\
$V_{p}, \mathrm{~V}$ & 18.0 & +0.2 & +0.5 \\
$V_{\text {th }}, \mathrm{V}$ & & -0.2 & -0.4 \\
& 27.0 & +0.3 & +0.6 \\
$R$ & & -0.3 & -0.6 \\
$Y(100)$ & 0.25 & +0.003 & +0.006 \\
& & -0.003 & -0.005 \\
$J_{k}, \mathrm{~A}$ & 0.060 & +0.001 & +0.002 \\
& & -0.001 & -0.002 \\
Throughput, kg & 0.224 & +0.003 & +0.005 \\
& & -0.002 & -0.005 \\
Time at 3.1-A, hrs & 253 & +22 & +48 \\
& & -19 & -37 \\
& 13,700 & +1200 & +2600 \\
\hline \hline
\end{tabular}

confidence bounds of +54 and $-41 \mathrm{~kg}$. Note that the small finite ion temperature used in this case results in a reduction in the median throughput of approximately $79 \mathrm{~kg}$. The nominal cases for both the cold ion and warm ion cases are the product of highly optimistic uncertainties in the experimental data used in the model. Uncertainty or variance in the plasma potential will result in the greatest uncertainty in the prediction. The sputter yield equation also contributes strongly to the prediction uncertainty. The cold ion case indicates that efforts to reduce the uncertainty in the plasma potential and the sputter yield equation will have the strongest impact on the wear prediction.

The nominal median throughput to erode the keeper orifice to the cathode tube diameter for the warm ion case is $253 \mathrm{~kg}$ with $96 \%$ confidence bounds of +48 and $-37 \mathrm{~kg}$. Unlike the cold ion case, an uncertainty of approximately $\pm 1 \mathrm{eV}$ ( $70 \%$ confidence) for the warm ion case results in $96 \%$ confidence bounds of +408 and $-145 \mathrm{~kg}$. The uncertainty in the plasma potential and the yield equation also contribute strongly to the uncertainty in the prediction. The accuracy of the double-to-single ion current weakly affects the prediction uncertainty. The results of this analysis indicate that evaluation of the ion temperature, the plasma potential within the discharge chamber, and the low-energy sputter yield are needed to reduce the uncertainty in predicting wear in the discharge chamber.

Additionally, the relatively simplistic model described by Eqs. (1) and (11) represents a limitation of the current investigation. More sophisticated analyses that contain more of the physics in the discharge chamber may shed new light on the ion generation regions and, thereby, more generally predict both the incident ion angles and energies, as well as the ion current distribution. These types of analyses may indicate operating regimes that minimize wear. The nominal probabilistic wear results indicate the limitation of the accuracy of any model based on Eq. (1). In cases where greater certainty is required, alternate modeling or experimental approaches should be considered, such as that described by Kolasinski and Polk. ${ }^{14}$

\section{Conclusions}

An experimental investigation was conducted to measure the ion current distribution to the keeper in the NEXT ion engine. Keeper ion current measurements were taken over the throttling range of the engine with several different keeper orifice diameters. The keeper ion current scaled with the beam current, and the average keeper ion current density for the NEXT engine was the same as that of the NSTAR engine for the same average beam current density. The radial distribution of the keeper ion current density was also calculated from the experimental data and was highly peaked near the orifice.

Table 7 Effect of the uncertainty in model parameters on the calculated throughput and time to wear keeper orifice to the cathode tube diameter at 3.1-A beam current for the warm ion case

\begin{tabular}{|c|c|c|c|c|c|c|c|c|c|}
\hline \multicolumn{4}{|c|}{ Varied parameter information } & \multicolumn{3}{|c|}{ Throughput, kg } & \multicolumn{3}{|c|}{ Time at 3.1-A, hrs } \\
\hline \multirow[b]{2}{*}{ Parameter } & \multirow[b]{2}{*}{ Median } & \multicolumn{2}{|c|}{ Confidence, $\%$} & \multirow[b]{2}{*}{ Median } & \multicolumn{2}{|c|}{ Confidence, $\%$} & \multirow[b]{2}{*}{ Median } & \multicolumn{2}{|c|}{ Confidence, $\%$} \\
\hline & & 70 & 96 & & 70 & 96 & & 70 & 96 \\
\hline \multirow[t]{2}{*}{$T_{i}, \mathrm{eV}$} & 5.00 & +0.53 & +1.16 & 253 & +60 & +140 & 13,700 & +3200 & +7500 \\
\hline & & -0.48 & -0.93 & & -44 & -81 & & -2400 & -4400 \\
\hline \multirow[t]{2}{*}{$T_{i}, \mathrm{eV}$} & 5.00 & +1.33 & +3.12 & 252 & +146 & +408 & 13,600 & +7900 & $+22,000$ \\
\hline & & -1.05 & -1.92 & & -88 & -145 & & -4800 & -7900 \\
\hline \multirow{2}{*}{$V_{p}, \mathrm{~V}$} & 18.0 & +2.0 & +5.0 & 254 & +90 & +231 & 13,700 & +4900 & $+12,500$ \\
\hline & & -1.7 & -3.1 & & -63 & -108 & & -3400 & -5800 \\
\hline \multirow[t]{2}{*}{$V_{\mathrm{th}}, \mathrm{V}$} & 27.0 & +2.9 & +6.2 & 253 & +51 & +125 & 13,700 & +2800 & +6700 \\
\hline & & -2.6 & -5.0 & & -37 & -63 & & -2000 & -3400 \\
\hline \multirow[t]{2}{*}{$R$} & 0.25 & +0.027 & +0.069 & 253 & +23 & +49 & 13,700 & +1200 & +2600 \\
\hline & & -0.024 & -0.043 & & -20 & -37 & & -1100 & -2000 \\
\hline \multirow[t]{2}{*}{$R$} & 0.25 & +0.068 & +0.193 & 253 & +25 & +56 & 13,700 & +1300 & +3000 \\
\hline & & -0.052 & -0.090 & & -22 & -40 & & -1200 & -2200 \\
\hline \multirow[t]{2}{*}{$Y(100)$} & 0.060 & +0.006 & +0.015 & 254 & +34 & +77 & 13,700 & +1900 & +4200 \\
\hline & & -0.006 & -0.010 & & -29 & -55 & & -1600 & -3000 \\
\hline \multirow[t]{2}{*}{$Y(100)$} & 0.060 & +0.016 & +0.041 & 254 & +81 & +204 & 13,700 & +4400 & $+11,000$ \\
\hline & & -0.012 & -0.021 & & -59 & -104 & & -3200 & -5600 \\
\hline \multirow[t]{2}{*}{$J_{k}, \mathrm{~A}$} & 0.224 & +0.024 & +0.055 & 253 & +35 & +79 & 13,700 & +1900 & +4300 \\
\hline & & -0.021 & -0.037 & & -29 & -54 & & -1600 & -2900 \\
\hline \multirow[t]{2}{*}{$J_{k}, \mathrm{~A}$} & 0.224 & +0.061 & +0.152 & 253 & +73 & 172 & 13,700 & +3200 & +7500 \\
\hline & & -0.045 & -0.078 & & -53 & 93 & & -2400 & -4400 \\
\hline
\end{tabular}


The experimental data were used to predict the wear of the keeper orifice. The model yielded the keeper radius as a function of throughput and operating time. The keeper orifice was predicted to erode to the cathode tube radius after processing 460 and $250 \mathrm{~kg}$ of xenon for the cold and warm ion assumptions, respectively. Although erosion to the cathode tube radius is significant, the analysis presented in this paper solely attempts to evaluate discharge cathode keeper orifice plate wear from ion bombardment. As was demonstrated in the ELT, severe erosion of the discharge cathode keeper orifice can be tolerated. ${ }^{13}$ The DS1 flight spare ion engine had processed only $31 \%$ of the propellant in the ELT after the discharge keeper orifice plate had enlarged to the cathode tube diameter. The NEXT discharge cathode keeper is predicted to reach the same condition after processing $63 \%$ of the total qualification throughput.

Finally, a probabilistic wear assessment was performed to understand better the effect of uncertainties in the input parameters on the accuracy of the wear prediction. The predicted wear of the keeper orifice appeared to be most sensitive to the ion temperature, the plasma potential, and the low-energy sputter yield. Consequently, the ability to predict the lifetime of discharge chamber components, as described in this work, is fundamentally tied to the accuracy with which the low-energy sputter yields, the plasma potential distribution, and the ion temperature are known. As the lifetime requirements for ion engines are increased dramatically over NSTAR for deep space missions, the ability to predict discharge chamber wear is becoming increasingly important, and alternate methods are necessary to yield significantly greater accuracy.

\section{References}

${ }^{1}$ Cassady, J. R., "Overview of Major U.S. Industrial Programs in Electric Propulsion," AIAA Paper 2001-3228, July 2001.

${ }^{2}$ DAWN website, http://www-ssc.igpp.ucla.edu/dawn/index.html [accessed 3 Nov. 2002].

${ }^{3}$ Bond, T. A., and Christensen, J. A., "NSTAR Ion Thrusters and Power Processors," NASA CR 1999-209162, Nov. 1999.

${ }^{4}$ Patterson, M. J., Foster, J. E., Haag, T. W., Soulas, G. C., Pastel, M. R., and Roman, R. F., "Thruster Development Status for NEXT: NASA'S Evolutionary Xenon Thruster," AIAA Paper 2003-4862, July 2003.

${ }^{5}$ Patterson, M. J., Rawlin, V. K., Sovey, J. S., Kussmaul, M. J., and Parkes, J., “2.3 kW Ion Thruster Wear Test,” AIAA Paper 95-2516, July 1995.

${ }^{6}$ Polk, J. E., Patterson, M. J., Brophy, J. R., Rawlin, V. K., Sovey, J. S., Myers, R. M., Blandino, J. J., Goodfellow, K. D., and Garner, C. E., "A 1000Hour Wear Test of the NASA NSTAR Ion Thruster," AIAA Paper 96-2717, July 1996

${ }^{7}$ Polk, J. E., Anderson, J. R., Brophy, J. R., Rawlin, V. K., Patterson, M. J., and Sovey, J. S., "The Effect of Engine Wear on Performance in the NSTAR 8000 Hour Ion Engine Endurance Test,” AIAA Paper 97-3387, July 1997.

${ }^{8}$ Polk, J. E., Anderson, J. R., Brophy, J. R., Rawlin, V. K., Patterson, M. J., Sovey, J. S., and Hamley, J., "An Overview of the Results of an 8200 Hour Wear Test of the NSTAR Ion Thruster," AIAA Paper 99-2446, June 1999.

${ }^{9}$ Anderson, J. R., Goodfellow, K. D., Polk, J. E., Shotwell, R. F., Rawlin, V. K., Sovey, J. S., and Patterson, M. J., "Results of an On-going Long Duration Ground Test of the DS1 Flight Spare Ion Engine," AIAA Paper 99-2857, June 1999.

${ }^{10}$ Domonkos, M. T., Foster, J. E., Patterson, M. J., and Williams, G. J., "Investigation of Keeper Erosion in the NSTAR Ion Thruster," 27th International Electric Propulsion Conf., IEPC Paper 01-308, 2001; also NASA TM-2001-211280, 2001.
${ }^{11}$ Anderson, J. R., Goodfellow, K. D., Polk, J. E., Rawlin, V. K., and Sovey, J. S., "Performance Characteristics of the NSTAR Ion Thruster During and On-Going Long Duration Ground Test," Inst. of Electrical and Electronics Engineers, IEEE Paper 8.0303, March 2000.

${ }^{12}$ Sengupta, A., Anderson, J., Brophy, J., Rawlin, V., and Sovey, J., "Performance Characteristics of the Deep Space 1 Flight Spare Ion thruster Long Duration Test After 21,300 Hours of Operation," AIAA Paper 2002-3959, July 2002

${ }^{13}$ Sengupta, A., Brophy, J. R., and Goodfellow, K. D., "Status of the Extended Life Test of the Deep Space 1 Flight Spare ion Engine After 30,352 Hours of Operation," AIAA Paper 2003-4558, July 2003.

${ }^{14}$ Kolasinski, R. D., and Polk, J. E., "Characterization of Cathode Keeper Wear by Surface Layer Activation,” AIAA Paper 2003-5144, July 2003.

${ }^{15}$ Soulas, G. C., Domonkos, M. T., and Patterson, M. J., "Performance Evaluation of the NEXT Ion Engine," AIAA Paper 2003-5278, July 2003

${ }^{16}$ Foster, J. E. and Patterson, M. J., "Plasma Emission Characteristics from a High Current Hollow Cathode in an Ion Thruster Discharge Chamber," AIAA Paper 2002-4102, July 2002.

${ }^{17}$ Herman, D. A., McFarlane, D. S., and Gallimore, A. D., "Discharge Plasma Parameters of a 30-cm Ion Thruster Measured without Beam Extraction using a High-Speed Probe Positioning System," 28th International Electric Propulsion Conf., IEPC Paper 03-0069, March 2003.

${ }^{18}$ Williams, G. J., "The Use of Laser-Induced Fluorescence to Characterize Discharge Cathode Erosion in a 30-cm Ring-Cusp Ion Thruster," Ph.D. Dissertation, Aerospace Engineering Dept., Univ. of Michigan, Ann Arbor, MI, 2000.

${ }^{19}$ Williams, G. J., Smith, T. B., and Gallimore, A. D., "30 cm Ion Thruster Discharge Cathode Erosion," 27th International Electric Propulsion Conf., IEPC Paper 01-306, Oct. 2001.

${ }^{20}$ Domonkos, M. T., and Stevens, R. E., "Assessment of Spectroscopic, Real-Time Ion Thruster Grid Erosion-Rate Measurements," AIAA Paper 2000-3815, July 2000.

${ }^{21}$ Rawlin, V. K., Sovey, J. S., Anderson, J. R., and Polk, J. E., "NSTAR Flight Thruster Qualification Testing," AIAA Paper 98-3936, July 1998.

${ }^{22}$ Mantenieks, M. A., "Sputtering Threshold Energies of Heavy Ions," 25th International Electric Propulsion Conf., IEPC Paper 97-187, Aug. 1997.

${ }^{23}$ Wilhelm, H. E., "Theoretical Investigation of Plasma Processes in the Ion Bombardment Thruster," NASA CR-134871, Oct. 1975.

${ }^{24}$ Kameyama, I., and Wilbur, P. J., "Measurements of Ions from High Current Hollow Cathodes Using Electrostatic Energy Analyzer," Journal of Propulsion and Power, Vol. 16, No. 3, 2000, pp. 529-535.

${ }^{25}$ Williams, G. J., Smith, T. B., Domonkos, M. T., Gallimore, A. D., and Drake, R. P., "Laser Induced Fluorescence Characterization of Ions Emitted from Hollow Cathodes," IEEE Transactions on Plasma Science, Vol. 28, No. 5, Oct. 2000, pp. 1664-1674.

${ }^{26}$ Beattie, J. R., and Matossian, J. N., "Mercury Ion Thruster Technology," NASA CR 174974, March 1989.

${ }^{27}$ Herman, D. A., and Gallimore, A. D., "Near Discharge Cathode Assembly Plasma Potential Measurements in a $30 \mathrm{~cm}$ NSTAR-type Ion Engine," AIAA Paper 2004-3958, July 2004.

${ }^{28}$ Duchemin, O. B., Brophy, J. R., Gamer, C. E., Ray, P. K., Shutthanandan, V., and Mantenieks, M. A., "A Review of Low Energy Sputtering Theory and Experiments," 25th International Electric Propulsion Conf., IEPC Paper 97-068, Aug. 1997.

${ }^{29}$ Rosenberg, D., and Wehner, G. K., "Sputtering Yields for Low Energy $\mathrm{He}^{+-}, \mathrm{Kr}^{+-}$, and $\mathrm{Xe}^{+-}$Ion Bombardment," Journal of Applied Physics, Vol. 33, No. 5, 1962, pp. 1842-1845.

${ }^{30}$ Stuart, R. V., and Wehner, G. K., "Sputtering Yields at Very Low Bombarding Ion Energies," Journal of Applied Physics, Vol. 33, No. 7, 1962, pp. $2345-2352$. 